\title{
Effect of Impacting Particle Kinetic Energy on Slurry Erosion Wear
}

\author{
Pankaj P. Shitole ${ }^{1,2} \cdot$ Shravan H. Gawande ${ }^{1}$ Girish R. Desale ${ }^{2}$ - Bhushan D. Nandre ${ }^{1,2}$
}

Received: 3 July 2015/Revised: 1 September 2015/Accepted: 7 September 2015/Published online: 13 October 2015

(c) Springer International Publishing AG 2015

\begin{abstract}
In the present investigation, the effect of kinetic energy of different materials of the same-sized solid particles is examined on copper as target material using slurry pot tester. Quartz, Silicon carbide and Alumina are the impacting solid particles used for conducting trials. It is understood that the kinetic energy and stress concentration of impacting particles on target surface are responsible for material removal from the target surface, also the effect of erodent property like its shape and density is more dominant at shallow impact angles compared to higher impact angles. However, it is reported in literature that the exponent of velocity varies from 1.87 to 4.00 for ductile materials. Thus, different materials with the same-sized solid particles at constant kinetic energy were used to conduct the experiments. It is observed that for three different materials mass loss for the same mean particle size is nearly constant at $90^{\circ}$ orientation angle but variation is found in $30^{\circ}$ orientation angle. Further, the SEM micrographs of these solid particles show that alumina have sharp edges and angular nature. Silicon carbide is sub-angular in nature while quartz is blocky in nature. SEM micrographs of eroded surfaces show that at shallow impact angles the material is mainly removed by the platelet mechanism and material is displaced in the direction of flow. Also it is observed that increasing the velocity for quartz particle increases the crater length as compared to other two materials. Erosion wear was found more when
\end{abstract}

Pankaj P. Shitole

pankaj13579@gmail.com

1 Department of Mechanical Engineering, M.E.S.College of Engineering, Pune, Maharashtra 411001, India

2 CSIR-National Chemical Laboratory, Pune, Maharashtra 411008, India alumina are used as the impacting particle due to their angular nature. At normal impact, indentation craters with rim are observed with significance increase in crater size when quartz is used as impacting particles.

Keywords Erosion wear - Kinetic energy - Slurry pot tester · Quartz · Silicon carbide · Alumina · Scanning electron microscope

\section{Introduction}

Material loss due to slurry erosion wear is a serious problem associated with flow of solid-liquid mixtures. Slurry erosion limits the life of the equipment and is, therefore, a critical parameter for design, selection and operation of the hydraulic transportation system. Engineering interest is to estimate the service life of equipment/components subjected to slurry erosion and to investigate the possibilities of enhancement of their life. Therefore, it is necessary to understand the parameters affecting erosion wear and to minimise them. A schematic diagram of erosion wear by solid particle impact is shown in Fig. 1. The slurry erosion is a complex phenomenon and it is not yet fully understood.

The solid particle's velocity, size, shape and concentration along with the properties of target material play an important role on material removal rate and its mechanism. The impact angle is defined as the angle between the target surface and the direction of impact velocity of the solid particle (see Fig. 1). It is generally agreed that the rate of mass loss due to erosion is a function of impact angle of particles [1]. The variation of the wear with impact angle is different for ductile and brittle materials as shown in Fig. 2. For ductile materials, the maximum erosion usually 


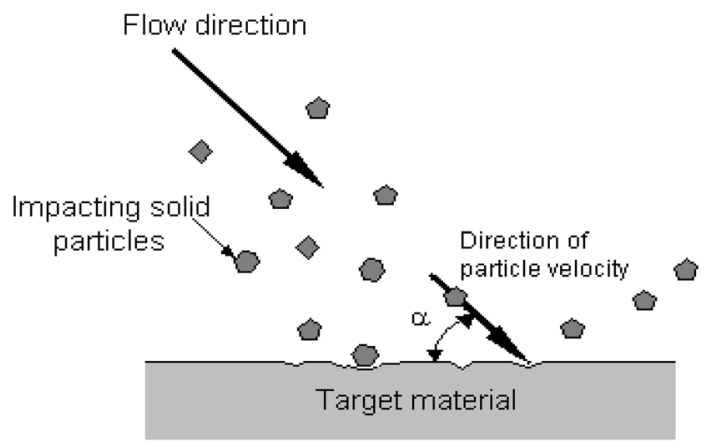

Fig. 1 Erosion wear by solid particles impact (Buckley 1981)

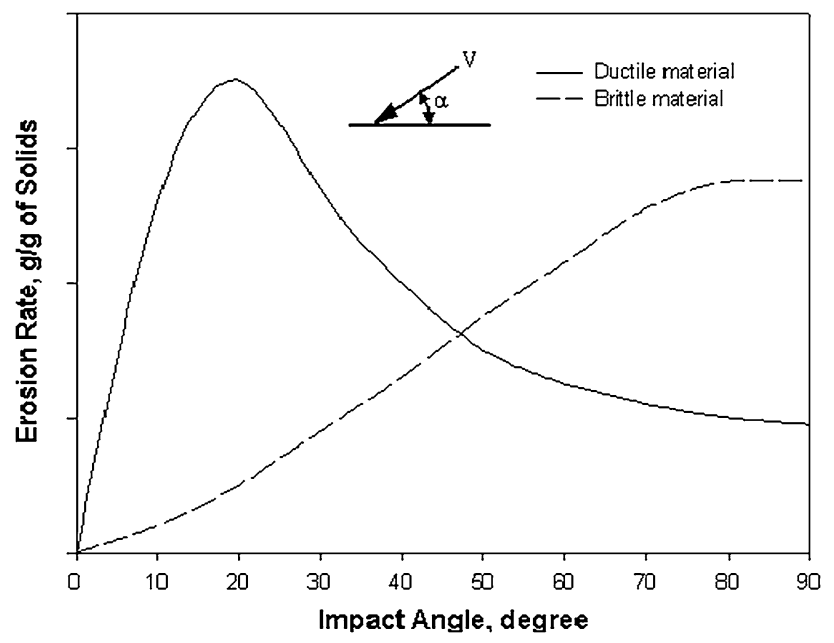

Fig. 2 Variation of erosion wear with impact angle

occurs around acute impact angle where as in brittle materials, the maximum erosion occurs at normal impact angle. The impact velocity has dominant effect on the material removal rate. The erosion rate is generally related to the particle velocity using power law relationship in which the power index for velocity varies in the range of 2-4 [2-6].

Bree et al. [2] found the power index in the range of 3-4. Oka et al. [7] and Desale [8] have observed the power index in the range of 2-3 and reported that it varies with the impact angle. Li et al. [9] and Levy et al. [10] found the power index as 2 and related the wear directly with the kinetic energy of impacting particles. The variation in the power index value of velocity may be attributed to the particle fragmentation, rotational energy of the particles and differences in experimental conditions [11]. The solid concentration can be expressed in terms of volume or weight concentration. Increase in solid concentration increases the number of solid particles impacting on the target material surface. This results in higher mass loss from the target surface at higher solid concentration. However, the erosion rate in terms of $\mathrm{g} / \mathrm{g}$ of solids may decrease with increase in solid concentration. This phenomenon can be attributed to decrease in collision efficiency, increased particle interaction and inter collision at higher solid concentrations, which results in lower mass removal rate per particle impact [12-16].

Accordingly, preliminary experiments using copper as target material and solid particles namely, quartz, silicon carbide and alumina are selected to study the effect of orientation angle on erosion rate. Many investigators have studied the effect of individual parameters like solid particles size, shape, impact velocity and concentration on erosion wear. While the kinetic energy of impacting solid particles have been used to develop the mathematical relations. Thus, three different erodents of similar size $(362.5 \mu \mathrm{m})$ at constant kinetic energy are used conduct the experiments.

\section{Experimental Program}

\subsection{Experimental Set Up}

A pot tester of $7.21 l$ capacity similar to one developed by Desale et al. [17] has been fabricated and used in the present study. Figure 3 shows the schematic diagram of the slurry pot tester with dimensional details. The AISI SS304L cylindrical pot of diameter of $240 \mathrm{~mm}$ and height of $155 \mathrm{~mm}$ is used to fabricate the slurry pot tester. Figure 4 shows the photographic view of fabricated pot for the slurry pot tester. Four baffles of size $10 \mathrm{~mm} \times 10 \mathrm{~mm} \times 155 \mathrm{~mm}$ are provided at the wall of cylindrical pot at equal distance to break the vortex motion produced due to the rotation of the propeller. At the bottom of the pot, a drain hole of $20-\mathrm{mm}$ diameter is provided to drain the solid-liquid mixture after the experiment. A 12-mm-thick transparent acrylic sheet is provided to cover the pot which is allowed for visual observations. The shaft is held in position by bearings assembly placed at a distance over the cover of the cylindrical pot. The shaft is coupled to the shaft of AC motor with love jaw coupling as shown in Fig. 3, and a hole of 11-mm diameter with oil-seal is provided at the bottom of the pot to insert a shaft for rotating the propeller. A PBT-4 propeller is mounted on this shaft to keep slurry in suspension at a distance of $24 \mathrm{~mm}$ above the bottom and is rotated by a $0.66 \mathrm{~kW}$ DC motor. This stainless steel pot is fixed on an iron-frame structure as shown in Fig. 3. A shaft is also inserted from the top of the tank through the transparent sheet to rotate the wear specimens at desired speeds by a separate $1.1185 \mathrm{~kW} 2 \mathrm{~A}$ AC motor. At lower end of the shaft, a brass sleeve of 30-mm length and 25- $\mathrm{mm}$ diameter is provided with provision for fixing two horizontal arms to hold two test fixtures. The fixing arrangement for test fixture is shown in Fig. 5. The indexing plate on which test fixture is mounted is shown in Figs. 6 and 7, respectively. 
Fig. 3 Schematic diagram of slurry pot tester
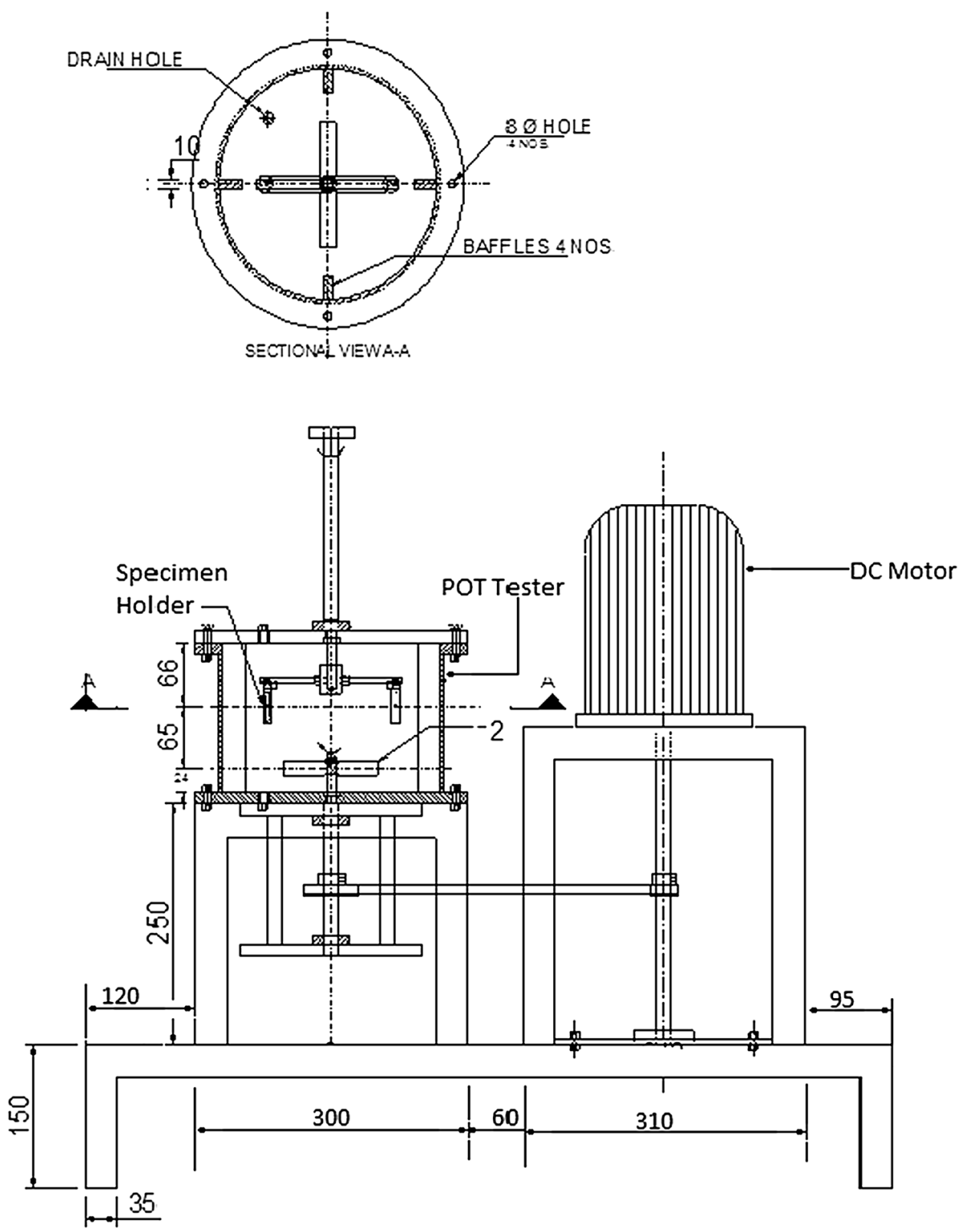

\subsection{Erodent and Target Material Properties}

In the present investigation, Indian Standard Sand (Quartz), Silicon Carbide and Alumina are used as erodent materials and Copper (Hardness: $120 \mathrm{Hv}$ ) as target material. Erodent material of the same size is practically difficult to be collected because natural erodents with uniform particle size can never be obtained [18]. Hence, the solid particles are sieved using available sieve sizes, and the particles collected between two successive sieves of sizes 425 and $300 \mu \mathrm{m}$ are used to prepare a solid-liquid mixture of mean particle size $362.5 \mu \mathrm{m}$. The physical properties of the erodents are given in Table 1.

In order to understand the particle shape, each erodent is examined using scanning electron microscope. Micrographs of the three erodents are shown in Fig. 8a-c. It is seen that particle shape of the three erodents is not the same. Quartz appears blocky in shape whereas silicon carbide has sub-angular shape and the alumina particles are angular with sharp cutting edges. The chemical composition of copper was determined using Optical emission spectrometer and its elemental composition is given in Table 2.

\subsection{Experimental Procedure and Test Conditions}

Fresh wear specimens are polished using \#2500 emery paper to keep identical initial conditions for each experiment. Wear specimens are cleaned with tap water, rinsed in acetone and dried with hot air blower before and after experiment. Mass loss of wear specimen is measured in electronic balance having least count of $0.1 \mathrm{mg}$. A solid- 


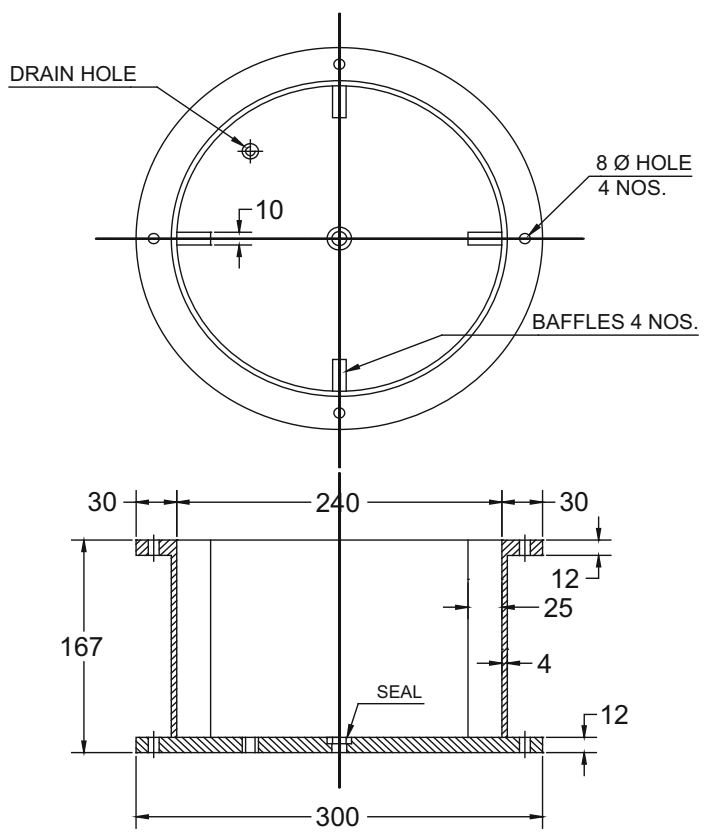

Fig. 4 Details of slurry pot

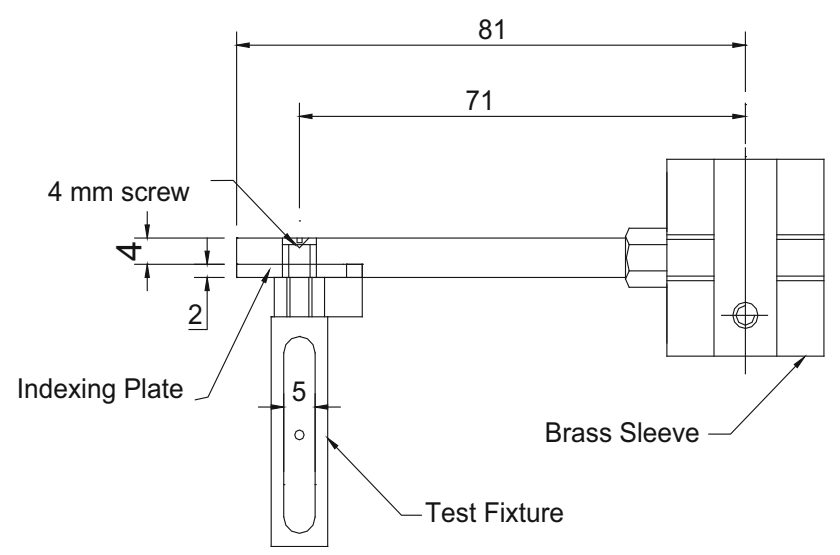

Fig. 5 Fixing arrangement for test fixture
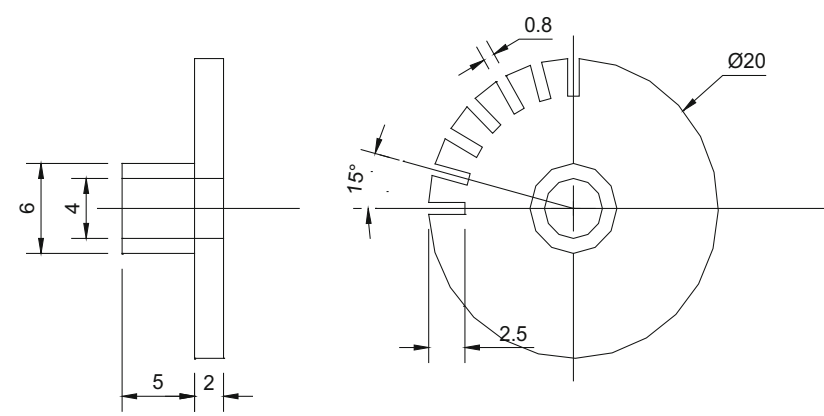

Fig. 6 Indexing plate

liquid mixture was prepared by mixing solid particles with water. For each test, the average mass loss of the two specimens is measured and used for further analysis.
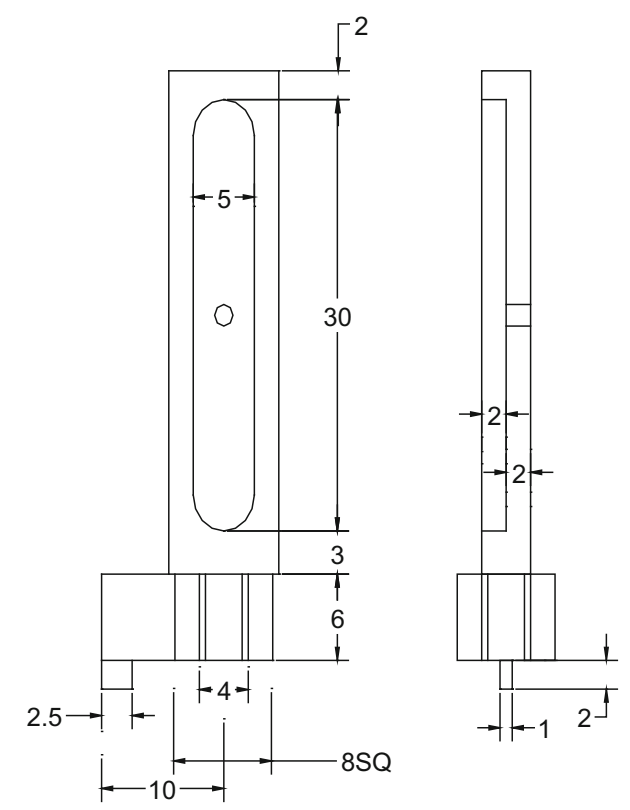

Fig. 7 Test fixture

Additionally, the worn out surfaces are examined using scanning electron microscope (SEM) to understand the wear mechanisms.

\subsection{Range of Parameters}

The preliminary experiments are conducted by orienting the test specimens in the range $7.5^{\circ}-90^{\circ}$, in the step of $15^{\circ}$ using three erodents namely quartz, silicon carbide and alumina of $362.5 \mu \mathrm{m}$ size with $10 \%$ by wt concentration and at $4 \mathrm{~m} / \mathrm{s}$ velocity. In order to investigate the effect of erodent's kinetic energy on material removal rate, the range of parameters applied is given in Table 3. Initially, for quartz particle $(362.5 \mu \mathrm{m})$, the experimental parameters, namely velocity $(5.5 \mathrm{~m} / \mathrm{s})$, solid concentration $(10 \%$ by wt) and test duration $\left(\alpha=30^{\circ}\right)$, were set. Accordingly, for the same-sized particles of silicon carbide and alumina the remaining parameters were determined to achieve constant kinetic energy.

To calculate the kinetic energy of solid particles and number of particles in the swept volume, the erodent particles were assumed spherical with $100 \%$ striking efficiency. Thus, the kinetic energy of individual Quartz, Silicon carbide and Alumina particle was calculated as $1.0 \times 10^{-6} \mathrm{~J}$. The numbers of quartz particles available in the pot tester for $10 \%$ by wt concentration were calculated as $\approx 11641090$. Accordingly, with approximately the same number of particles for silicon carbide and alumina, the solid concentration (\% by wt) was determined. Thus, it was ensured that the numbers of solid particles in the swept volume of test specimen for one rotation were kept 
Table 1 Physical properties of erodents (supplier's data)

\begin{tabular}{llllll}
\hline Solid particle & Chemical formula & Colour & Specific gravity $\left(\mathrm{kg} / \mathrm{m}^{3}\right)$ & Hardness $($ VHN) & Particle shape \\
\hline Quartz (IS Sand) & $\mathrm{SiO}_{2}$ & Whitish & 2652 & 1100 & Blocky \\
Silicon carbide & $\mathrm{SiC}$ & Blackish & 3210 & 2500 & Sub-angular \\
Alumina & $\mathrm{Al}_{2} \mathrm{O}_{3}$ & Brown & 3970 & 1800 & Angular \\
\hline
\end{tabular}
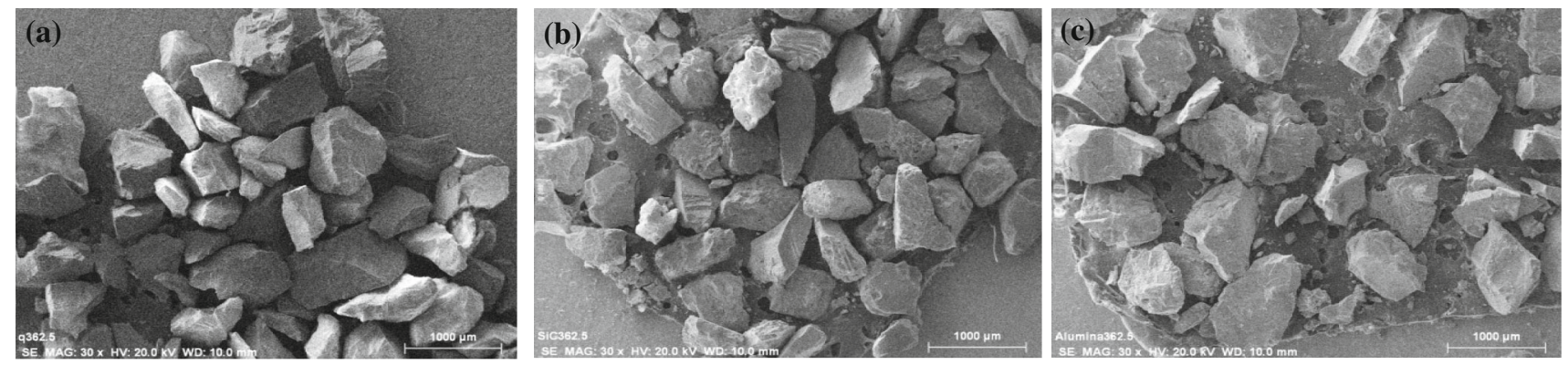

Fig. 8 SEM images of erodents $(d=362.5 \mu \mathrm{m})$. a Quartz b Silicon carbide c Alumina

Table 2 Elemental composition of copper (wt $\%$ )

\begin{tabular}{lllllllll}
\hline $\mathrm{Cu}$ & $\mathrm{Sn}$ & $\mathrm{Pb}$ & $\mathrm{Zn}$ & $\mathrm{C}$ & $\mathrm{S}$ & $\mathrm{Ni}$ & $\mathrm{Sb}$ & $\mathrm{Fe}$ \\
\hline 82.72 & 2.47 & 0.005 & 10 & 1.73 & 0.60 & 1.0 & 0.25 & 0.2 \\
\hline
\end{tabular}

constant. However, the change in velocity of solid particles to achieve the constant kinetic energy leads to change in the rpm during experiments. In order to keep total number of particles constant $(\approx 2311797900)$ in the swept volume, the test duration was determined and experiments were conducted accordingly.

\section{Results and Discussion}

The variations in erosion rate with orientation angle for solid-liquid mixture of three natural erodents namely quartz, silicon carbide and alumina are presented graphically in Fig. 9 with copper as target material. It is seen that target material shows maximum wear at shallow impact angles with all the three erodents, which is generally observed for ductile materials [2, 4]. The maximum erosion wear is observed at around $30^{\circ}$ orientation angle using quartz and silicon carbide erodents while erosion wear is maximum at around $22.5^{\circ}$ orientation angle using alumina erodent.

The average mass losses of the copper test specimens were determined for the same mean particle size at $30^{\circ}$ and $90^{\circ}$ orientation angles and are graphically presented in Fig. 10 The mean of average mass loss for the same particle size at $30^{\circ}$ and $90^{\circ}$ orientation angle is observed to be 0.0163 and $0.0047 \mathrm{~g}$, respectively. Though the particles are impacting with the same kinetic energy at $30^{\circ}$ and $90^{\circ}$ orientation angles the mass loss is different and this can be attributed to the change in the material removal mechanism [19]. The experiments were conducted at different impact velocities and for different test durations for similar mean particle size to maintain the same kinetic energy $\left(1.0 \times 10^{-6} \mathrm{~J}\right)$ of individual impacting particles and consequently the same total kinetic energy dissipated on the target surface was found to be $2311.80 \mathrm{~J}$.

The wear at shallow angle is mainly caused by the velocity of the particle parallel to the target surface and is generally compared with the material removal by a machine during metal cutting process [20, 21]. Impact energy and particle shape may play a significant role at shallow angles because the angular particle shape may have a number of cutting edges, which may penetrate deep
Table 3 Range of parameters to investigate the effect of kinetic energy of quartz, silicon carbide and alumina on erosion wear of copper at $30^{\circ}$ and $90^{\circ}$ orientation angle (mean particle size: $362.5 \mu \mathrm{m})$

\begin{tabular}{llllc}
\hline Erodent material & Velocity $(\mathrm{m} / \mathrm{s})$ & Solid concentration $(w t \%)$ & \multicolumn{2}{c}{ Test duration (min:s) } \\
\cline { 3 - 5 } & & & $\alpha=30^{\circ}$ & $\alpha=90^{\circ}$ \\
\hline Quartz & 5.5 & 10.00 & $30: 00$ & $15: 00$ \\
Silicon carbide & 4.94 & 12.35 & $33: 35$ & $16: 41$ \\
Alumina & 4.45 & 15.28 & $37: 09$ & $18: 35$ \\
\hline
\end{tabular}




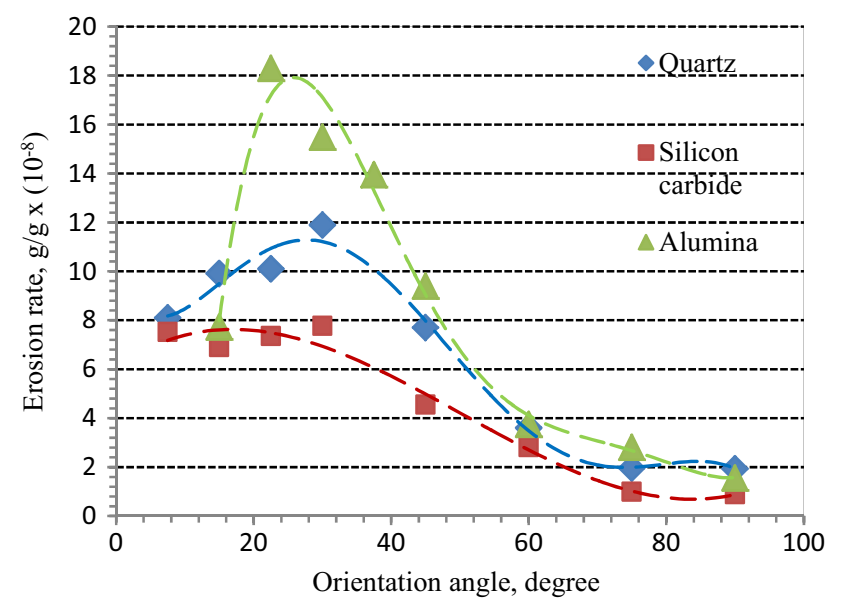

Fig. 9 Erosion rate of copper using quartz, silicon carbide, and alumina $\left(d=362.5 \mu \mathrm{m}, v=4 \mathrm{~m} / \mathrm{s}, c_{\mathrm{w}}=10 \%\right)$

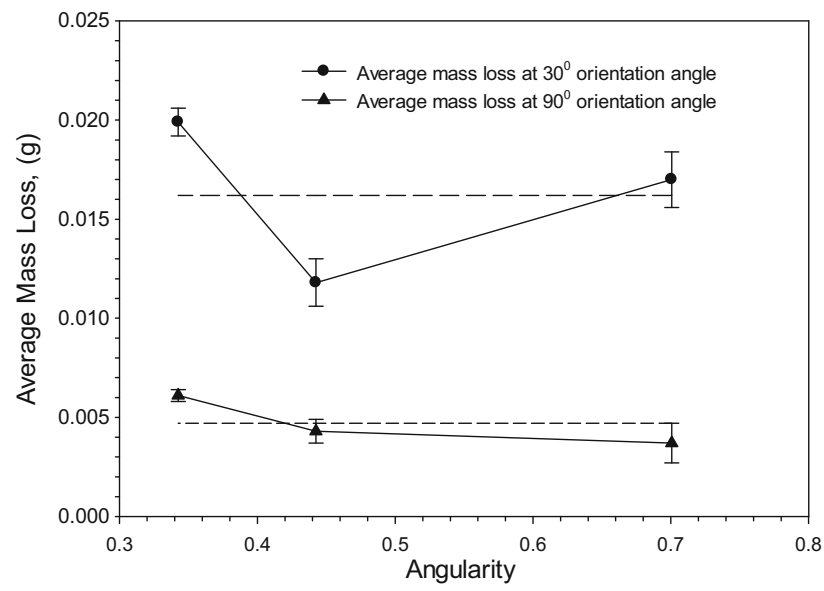

Fig. 10 Effect of angularity on average mass loss at $30^{\circ}$ and $90^{\circ}$ orientation angle $(d=362.5 \mu \mathrm{m})$

at the surface with higher impact energy. For the same particle size impact energy varies directly with the mass density, which is highest for alumina and lowest for quartz. Thus, the combined effect of particle shape and its density makes it difficult to quantify the effect of individual parameters. Hence shape of erodent is an important property and has a more dominating effect on erosion wear than its density alone.

It has been reported that the erosion wear increases with increase in angularity of erodents [18, 22, 23]. It can be seen that the two particles, having the same size but different shapes, may exhaust the same energy at the target surface under similar experimental conditions but area of contact will be different in each case. The effective radius of contact at the surface may be less for an angular particle compared to spherical particle. This reduction in contact area leads to increase in the kinetic energy dissipated per unit area, leading to higher stress intensity capable of removing larger material. Quartz particle appears blocky in shape, silicon carbide is sub-angular in shape whereas alumina particle appears to be more angular and depicts higher slenderness ratio compared to that of the silicon carbide particles.

\subsection{SEM Examination}

Micrographs of worn out specimens have been examined through scanning electron microscope (SEM). The micrographs at maximum wear angle of copper are presented in Fig. 11. It is observed from the figure that the wear of copper by blocky shape quartz particles may be due to deformation due to ploughing and displacing the material in the flow direction. The rim of displaced material is formed in the flow direction and appears as the terminal lip. The ploughing type craters formed on copper target material are also wider in width due to sub-angular shaped silicon carbide particles. However, quartz particles remove material from the target surface by ploughing, displacing the material and also there is some contribution of cutting as shown in Fig. 11. The craters formed in this case are longer and less in width compared to the craters formed due to the impact of sub-angular shaped silicon carbide particles, whereas, angular shaped alumina particles having sharp cutting edges remove the material with major contribution by cutting rather than ploughing. This also gives evidence that cutting mechanism removes the material more effectively than ploughing. The narrow and deep craters are formed due to the impact of alumina particles which are different than that formed by other two particles.

Similarly, the material removal mechanism due to impact of different erodents at normal impact condition is taken as a representative of deformation wear and is shown in SEM micrographs in Fig. 12. It can be seen from the figure that the ploughing and smear type craters disappeared, and indentation craters are formed due to the normal impact of the erodents.

Due to the normal impact of blocky shaped quartz particles, material surface is deformed in the form of flakes, which may be flattened due to successive impact of quartz particles. However, it is observed from Fig. 12 that for angular particles of alumina the indentation crater displaces the material, forming a rim around the crater due to the particle impact. Thus, the material may be removed by both the deformation and rotation of cutting edges in case of normal impact of angular particles.

\subsection{Software Program}

The sand particles of certain mass and definite velocity are rotated in slurry pot, and because these sand particles have certain measure of kinetic energy, the erosion wear of 

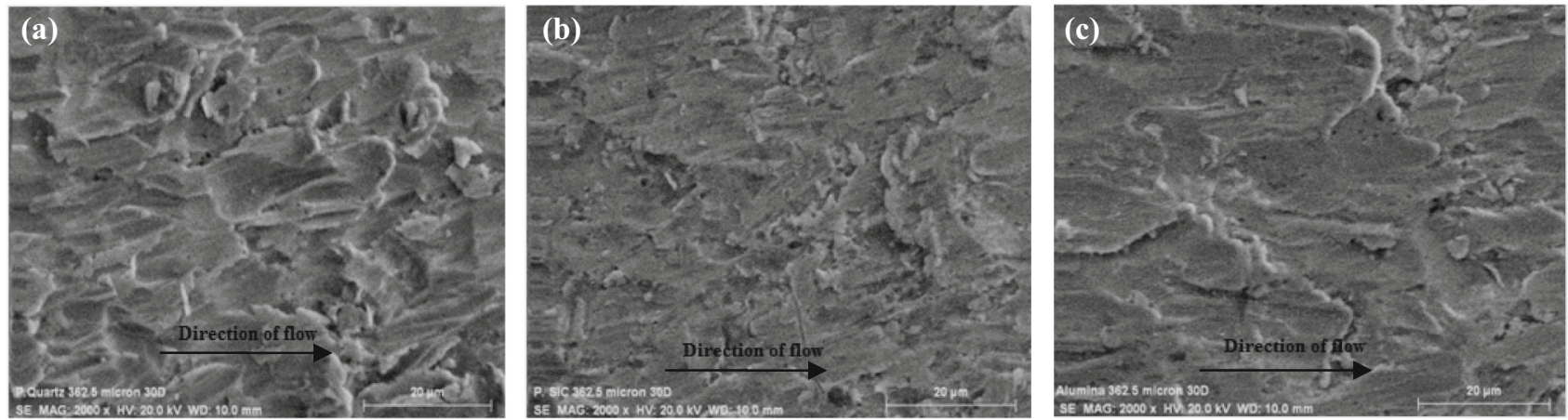

Fig. 11 Mechanism of material removal at $30^{\circ}$ orientation angle for constant kinetic energy of particles (target material: copper; erodent: IS sand, silicon carbide, alumina, particle size $d=362.5 \mu \mathrm{m}$ ). a $\quad v=5.5 \mathrm{~m} / \mathrm{s}, \quad c_{\mathrm{w}}=10 \%$ b $\quad v=4.94 \mathrm{~m} / \mathrm{s}, \quad c_{\mathrm{w}}=12.35 \%$ c $v=4.45 \mathrm{~m} / \mathrm{s}, c_{\mathrm{w}}=15.28 \%$
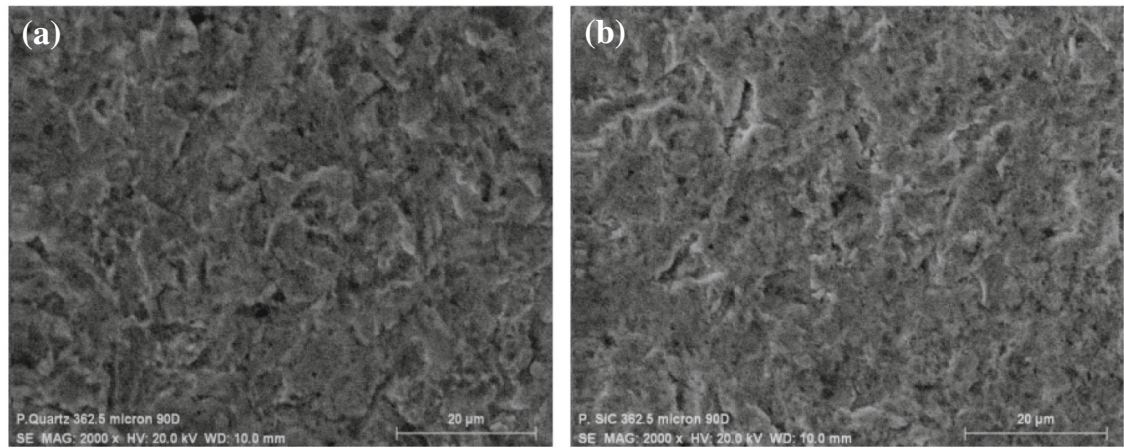

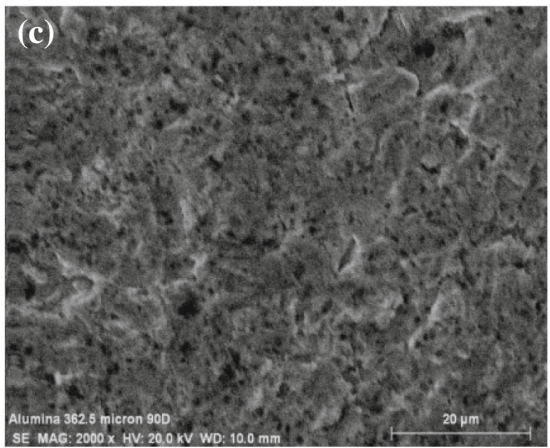

a $\quad v=5.5 \mathrm{~m} / \mathrm{s}, \quad c_{\mathrm{w}}=10 \%$

b $\quad v=4.94 \mathrm{~m} / \mathrm{s}, \quad c_{\mathrm{w}}=12.35 \%$ c $v=4.45 \mathrm{~m} / \mathrm{s}, c_{\mathrm{w}}=15.28 \%$

experimental investigations e.g., copper plate is kept fixed while solid quartz particle has the given respective velocity. The solid particle is assumed to be spherical while analysis work and explicit dynamics is used in it.

The stress concentration of solid particle impacting on plate might be a parameter due to which the loss of material takes place. The quartz solid particle of size $362.5 \mu \mathrm{m}$ impacts with $5.50 \mathrm{~m} / \mathrm{s}$ velocity on copper plate due to which von-Mises stress at contacting area and total deformation of solid particle takes place. The values of von-Mises stress and total deformation is given in Fig. 13 (Table 5).

\section{Conclusion}

The main objective of this paper is to study the effect of kinetic energy of different materials of the same-sized solid particles. This objective is achieved by performing extensive experiments on slurry pot tester. During experimentation, it is found that the erosion rate of ductile materials varies with the erodent properties other than their size. The 

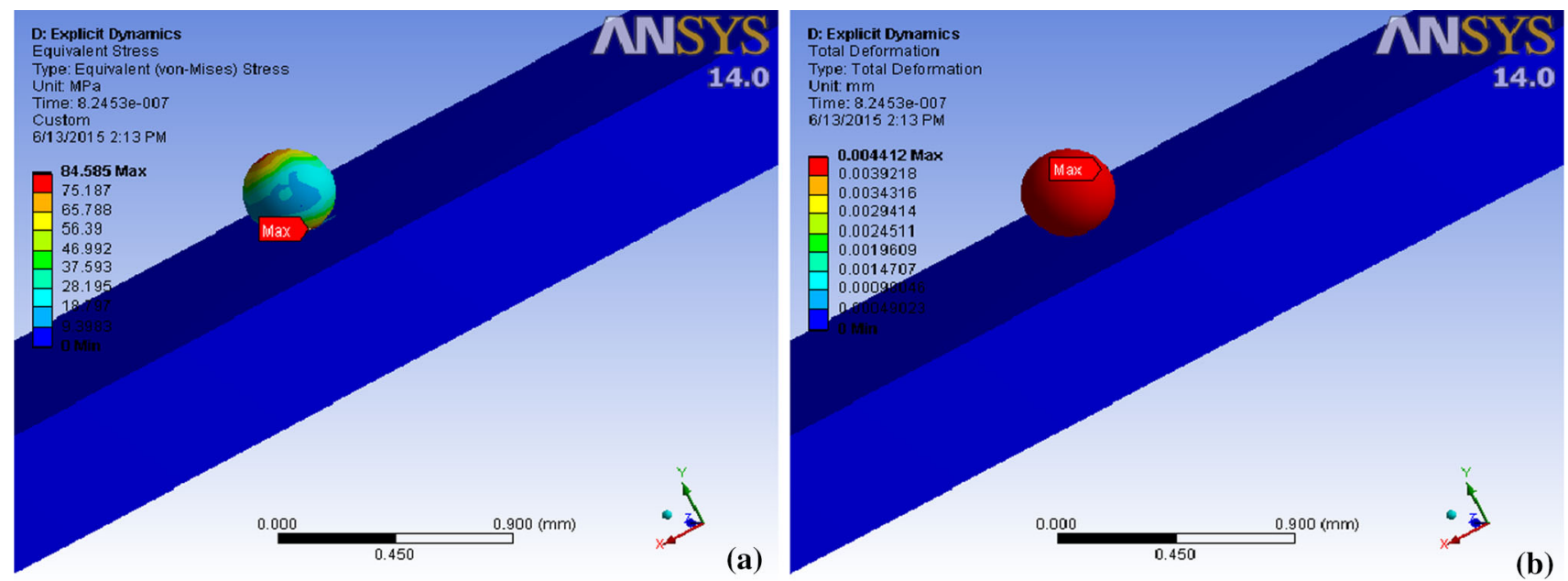

Fig. 13 a von-Mises stress b total deformation of quartz particle on copper plate as target

Table 4 Physical properties of quartz

\begin{tabular}{ll}
\hline Physical property & Values \\
\hline Poisson's ratio & 0.17 \\
Young's modulus & $74.8 \mathrm{GPa}$ \\
Density & $2652 \mathrm{~kg} / \mathrm{m}^{3}$ \\
\hline
\end{tabular}

Table 5 FEA results shows the simulated values of various parameters such as von-Mises stress and deformation

\begin{tabular}{ll}
\hline Solid particle size $(\mu \mathrm{m})$ & 362.5 \\
Velocity $(\mathrm{m} / \mathrm{s})$ & 5.50 \\
von-Mises stress $(\mathrm{MPa})$ & 84.585 \\
Total deformation $(\mathrm{mm})$ & 0.004412 \\
\hline
\end{tabular}

effect of erodent property like its shape is more dominant at shallow impact angles (i.e. $7.5^{\circ}-45^{\circ}$ ) as compared to higher impact angles (i.e. $90^{\circ}$ ). Again during experimentation it is seen that the mass loss due to erosion is a function of kinetic energy. The material removal mechanism appears to be a function of erodents' shape. Solid particle having higher angularity (lower shape factor) produces deep craters and generates higher mass loss as compared to particles having low angularity (higher shape factor). Thus, erosion rate by dense and angular particles is significantly high. From numerical analysis it is perceived that the stress concentration of solid particle on target surface is also responsible for erosion wear.

Acknowledgments The authors gratefully acknowledge the financial support from CSIR-NCL Pune and are thankful to Dr. Sourav Pal, Director, and Dr. Vivek Ranade, Chair, CEPD Division, CSIR-NCL, Pune.

\section{Compliance with Ethical Standards}

Conflict of Interest The authors declare that there is no conflict of interests regarding the publication of this paper.

\section{References}

1. Tsai W, Humphrey JAC, Cornet I (1981) Experimental measurement of accelerated erosion in a slurry pot tester. Wear 68:289-303

2. de Bree SEM, Rosenbrand WF, de Gee AWJ (1982) On the erosion resistance in water-sand mixtures of steels for application in slurry pipelines, Hydrotransport 8, BHRA Fluid Engineering, Johannesburg, (S.A.), Paper C3

3. Elkholy A (1983) Prediction of abrasion wear for slurry pump materials. Wear 84:39-49

4. Lin FY, Shao HS (1991) Effect of impact velocity on slurry erosion and a new design of a slurry erosion tester. Wear 143:231-240

5. Gupta R, Singh SN, Seshadri V (1995) Prediction of uneven wear in a slurry pipeline on the basis of measurements in a pot tester. Wear 184:169-178

6. Gandhi BK, Singh SN, Seshadri V (1999) Study of the parametric dependence of erosion wear for the parallel flow of solid-liquid mixtures. Tribol Int 32:275-282

7. Oka YI, Okamura K, Yoshida T (2005) Particles estimation of erosion damage caused by solid particle impact Part 1: effect of impact parameters on a predictive equation. Wear 259:95-101

8. Desale GR (2007) Ph.D Thesis, Slurry erosion behaviour of SS304L, AA6063 copper ductile type material and laser cladded surface. IIT (Roorkee)

9. Li SK, Humphrey JAC, Levy AV (1981) Erosion wear of a ductile metals by a particle-laden high velocity liquid jet. Wear 73:295-309

10. Levy AV, Yau P (1984) Erosion of steels in liquid slurries. Wear 98:163-182

11. Finnie I (1960) Erosion of surfaces by solid particles. Wear 3:87-103

12. Mens IWM, de Gee AWJ (1986) Erosion in seawater sand slurries. Tribol Int 19:59-64 
13. Clark HM (1991) On the impact rate and impact energy of particles in a slurry pot erosion tester. Wear 147:165-183

14. Levy AV (1986) The platelet mechanism of erosion of ductile metals. Wear 108:1-21

15. Desale GR, Gandhi BK, Jain SC (2006) Effect of erodent properties on erosion wear of ductile type materials. Wear 261(7-8):914-921

16. Desale GR, Gandhi BK, Jain SC (2005) Effect of physical properties of solid particle on erosion wear of ductile materials. In: Proceedings of 2005 ASME World Tribology Congress III, Washington, DC

17. Desale GR, Gandhi BK, Jain SC (2003) Suspension of sand particles in a cylindrical water pot due to rotation of a propeller. In: 30th National conference on fluid mechanics and fluid power, Surathkal, pp 528-534
18. Levy AV (1995) Solid particle erosion and erosion-corrosion of materials. ASM International, Materials Park

19. Levy AV, Chik P (1983) The effects of erodent composition and shape on the erosion of steel. Wear 89:151-162

20. Finnie I (1972) Some observations on the erosion of ductile metals. Wear 19:81-89

21. Finnie I, McFadden DH (1978) On the velocity dependence of the erosion of ductile metals by solid particles at low angles of incidence. Wear 48:181-190

22. Levy AV, Hickey G (1987) Liquid-solid particle slurry erosion of steels. Wear 117:129-146

23. Bahadur S, Badruddin R (1990) Erodent particle characterization and the effect of particle size and shape on erosion. Wear 138:189-208 